\title{
Bidirectional semantic priming in the attentional blink
}

\author{
MARY C. POTTER \\ Massachusetts Institute of Technology, Cambridge, Massachusetts \\ ROBERTO DELLACQUA, FRANCESCA PESCIARELLI, \\ REMO JOB, and FRANCESCA PERESSOTTI \\ University of Padua, Padua, Italy \\ and \\ DANIEL H. O'CONNOR \\ Massachusetts Institute of Technology, Cambridge, Massachusetts
}

\begin{abstract}
The time course of semantic priming between two associated words was tracked using rapid serial visual presentation of two synchronized streams of stimuli appearing at about 20 items/sec, each stream including a target word. The two words were semantically related or unrelated and were separated by stimulus onset asynchronies (SOAs) of 0-213 msec. Accuracy in reporting the first target (T1) versus the second target (T2) has been shown to interact dramatically with SOA over this range. The materials were in English in Experiment 1 and Italian in Experiment2. T1 was semantically primed only at short SOAs, whereas T2 was primed at all SOAs (Experiment 1) or at all SOAs except the shortest one (Experiment2). The results indicate a strong competition between target words early in processing, with T2 often becoming the first word identified at short SOAs, thus priming T1.
\end{abstract}

Human observers possess the remarkable ability to report a visual target even when it is embedded in a rapid serial visual presentation (RSVP) stream of spatially overlapping distractors. However, when two such targets must be reported (conventionally, T1 and T2), report of T2 is severely impaired, even when the rate of presentation is as slow as $8-10$ items/sec (e.g., Broadbent \& Broadbent, 1987). This deficit, termed the attentional blink (AB) by Raymond, Shapiro, and Arnell (1992), is typically observed when the stimulus onset asynchrony (SOA) between $\mathrm{T} 1$ and T2 is between 200 and $500 \mathrm{msec}$, and disappears when the SOA is $600 \mathrm{msec}$ or longer. Several AB studies have shown, however, that when $\mathrm{T} 1$ and $\mathrm{T} 2$ are immediately successive (at an SOA of about $100 \mathrm{msec}$ ) the $\mathrm{AB}$ effect is often reduced or eliminated, an effect called lag-1 sparing (Potter, Chun, Banks, \& Muckenhoupt, 1998).

Most AB studies have used a single stream of stimuli presented at about $100 \mathrm{msec} /$ item, meaning that SOAs shorter than $100 \mathrm{msec}$ could not be investigated. However, when these constraints were avoided, a crucial finding emerged. Potter, Staub, and O'Connor (2002) presented word targets in two streams of stimuli, one directly

This work was supported by FIRB Grant RBAU01LE9P from the Italian Ministry of University to R.D.A. and by Grant MH47432 from the National Institute of Mental Health to M.C.P. D.H.O. is now at Princeton University. We thank Laura Fox for her assistance. Correspondence should be addressed to M. C. Potter, Department of Brain and Cognitive Sciences, NE20-453, Massachusetts Institute of Technology, Cambridge, MA 02139 (e-mail: mpotter@mit.edu). above the other, at $53 \mathrm{msec} /$ item, replicating previous results showing an $\mathrm{AB}$ for $\mathrm{T} 2$ at an $\mathrm{SOA}$ of $213 \mathrm{msec}$ and sparing of T2 at an SOA of $107 \mathrm{msec}$ (lag 2 in this experiment). Surprisingly, however, at an SOA of $53 \mathrm{msec}$ (lag 1) T2 report was significantly better than T1 report, the reverse of the $\mathrm{AB}$ effect. The advantage of $\mathrm{T} 2$ over $\mathrm{T} 1$ was obtained at SOAs as short as $13 \mathrm{msec}$ and extended to SOAs of 53 and sometimes $107 \mathrm{msec}$.

Potter et al. (2002) proposed a two-stage competition model to account for these results. Stage 1 begins when T1 is detected as a potential target, opening an attentional window, and ends when it is lexically identified. During Stage 1 processing of T1, the onset of T2 draws resources away from $\mathrm{T} 1$ : The two targets are in competition. At very short SOAs of $53 \mathrm{msec}$ or less, T2 is hypothesized to gain a competitive edge over T1 because T2 benefits from the already-open attentional window, often allowing T2 to be identified first. At longer SOAs, however, there is an increasing probability that $\mathrm{T} 1$ will be the first to be identified. Crucially, the first-identified target (whether T1 or T2) enters Stage 2, in which shortterm consolidation of the target occurs, allowing it to be reported (Chun \& Potter, 1995; Jolicœur \& Dell'Acqua, 1998). Stage 2 is serial, a bottleneck lasting several hundred milliseconds, in which only one target can be processed. The other target must wait for entrance to Stage 2 and is vulnerable to forgetting or erasure (e.g., Dell'Acqua, Pascali, Jolicœur, \& Sessa, 2003).

Targets identified in Stage 1 are also represented at least briefly in conceptual short-term memory (CSTM; 


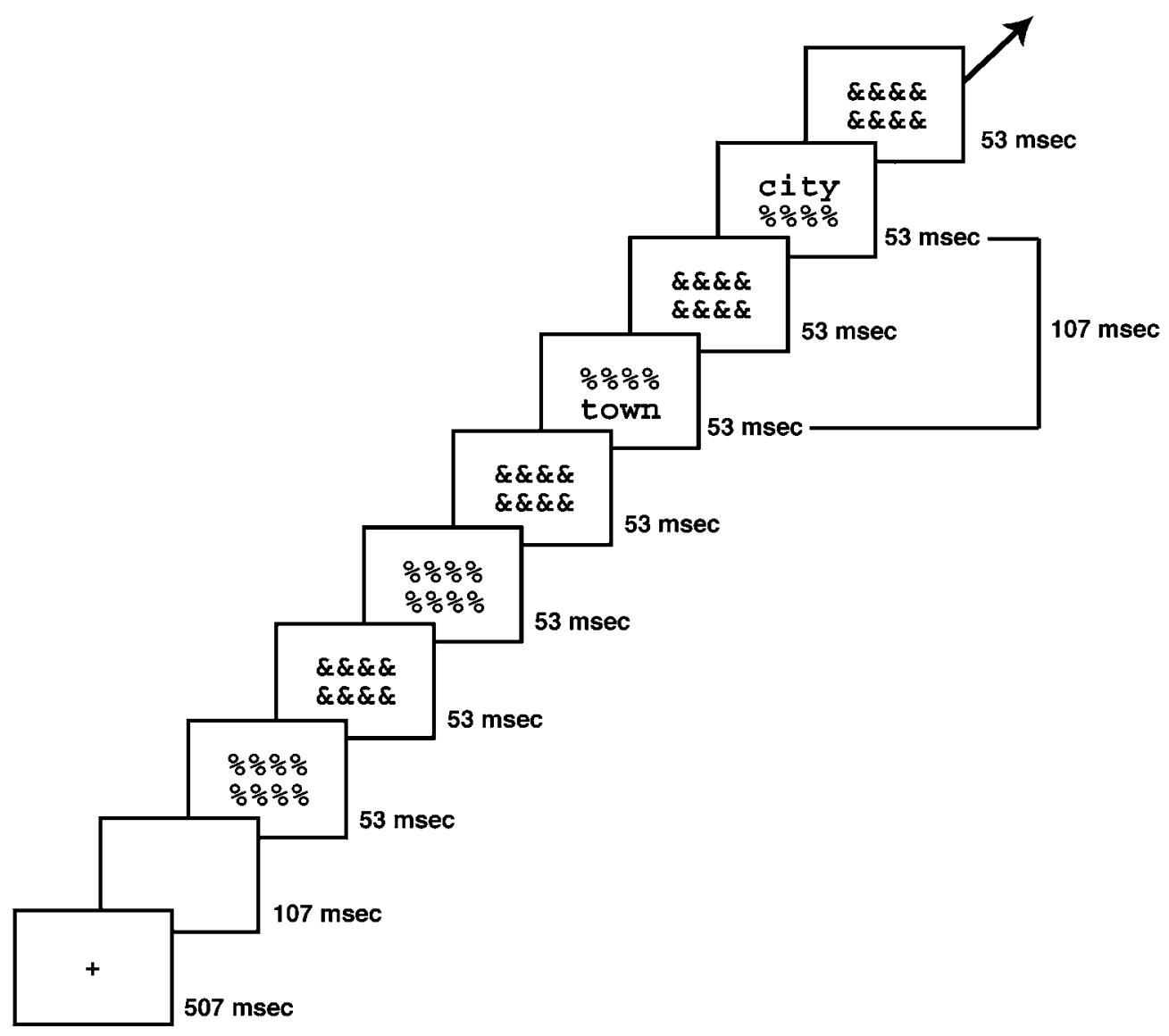

Figure 1. Schematic representation of the sequence of events on a trial in Experiment 1.

Potter, 1999). Evidence for this assumption comes from studies showing that a semantic association between $\mathrm{T} 1$ and $\mathrm{T} 2$ increases the likelihood that $\mathrm{T} 2$ will be reported. For example, Juola, Duvuru, and Peterson (2000) presented word targets in different streams at $120 \mathrm{msec} /$ item and found that priming from $\mathrm{T} 1$ to $\mathrm{T} 2$ was constant over SOAs of $120-600 \mathrm{msec}$, since the proportion of T2 words reported in the unprimed condition rose from .26 to .70 over that $\mathrm{SOA}$ range. The presence of a sizable $\mathrm{AB}$ did not block associative priming, suggesting that the meaning of each word had been retrieved at a stage of processing before that critical to generate an $\mathrm{AB}$ effect. Maki, Frigen, and Paulson (1997) obtained a similar result in a one-stream experiment with words presented at $100 \mathrm{msec} / \mathrm{item}$. The electrophysiological evidence collected by Vogel, Luck, and Shapiro (1998) points to conceptually identical conclusions (see also Rolke, Heil, Streb, \& Hennighausen, 2001).

The implicit assumption underlying $\mathrm{AB}$ studies of semantic priming is that when T1 is identified in Stage 1, it establishes a semantic context that modulates the outcome of Stage 1 processing of T2. The competition model proposed by Potter et al. (2002) makes a counterintuitive prediction concerning the direction of semantic priming effects between $\mathrm{T} 1$ and $\mathrm{T} 2$ when the SOA is shorter than
$100 \mathrm{msec}$. If we assume that the first-identified target acts as a prime of the other target, the competition model predicts that at short SOAs, when $\mathrm{T} 2$ is frequently identified before T1, T2 will prime T1. At longer SOAs, when T1 is almost always identified first, only T2 will be primed.

Experiments 1 and 2, in English and Italian, respectively, were carried out independently and concurrently in two separate labs using similar designs but different stimuli. In each experiment, participants were instructed to report two semantically related or unrelated target words that were presented in dual streams at variable SOAs.

\section{EXPERIMENT 1}

\section{Method}

Participants. Sixteen volunteers, all native English speakers, were paid for participating.

Stimuli and Apparatus. The target stimuli were 128 associatively or semantically related pairs of words (e.g., sugar-candy). Most of the words were nouns; some were adjectives or verbs. Many pairs were taken from association norms or norms for category membership; others were generated by the experimenters. Word frequency was not controlled. The members of a given pair were the same length, either four or five letters. The pairs of a given length were re-paired to form unrelated pairs. The distractor stimuli were strings of ampersands and strings of percentage signs, the same length as the words on a given trial. We used Courier 20 bold 
font in lower case. The stimuli were presented on a Power Macintosh 7500/100 computer equipped with a 17-in. monitor with a refresh rate of $75 \mathrm{~Hz}$, using MacProbe software (Hunt, 1994). When viewed from the normal distance of $45 \mathrm{~cm}$, the four-letter words subtended $2^{\circ}$ horizontally and $.55^{\circ}$ vertically and were separated by a space of $.4^{\circ}$. The words and distractors were black on a light gray background; the room was normally illuminated.

Design and Procedure. Figure 1 shows the sequence of events on a trial in Experiment 1. The presentation duration was $53 \mathrm{msec} /$ item. The SOAs between the words were 27, 53, 107, and $213 \mathrm{msec}$. (At $27 \mathrm{msec}$, the two words overlapped for $27 \mathrm{msec}$.) Within subjects, T1 was equally often in the upper or lower stream; T2 was always in the other stream. Relatedness was counterbalanced with SOA and with which word appeared first. Four distractors preceded $\mathrm{T} 1$ and five followed T2. The participants then typed the two words, in any order. The correct words were presented for $2 \mathrm{sec}$ as feedback. There were 128 trials and 21 practice trials. No target word was ever repeated.

\section{Results}

Each word was scored separately as correct or incorrect. The main analysis of variance (ANOVA) was performed on the proportion of correct words reported in each of 16 conditions, $4 \mathrm{SOAs} \times \mathrm{T} 1 / \mathrm{T} 2 \times$ related/unrelated words. Figure 2 shows the main results.

Related words were reported much more accurately (.61 correct) than were unrelated words $[.52$ correct; $F(1,15)=49.83, p<.001]$, and $\mathrm{T} 1$ was reported more accurately $(.65$ correct) than was $\mathrm{T} 2$ [.47 correct; $F(1,15)=35.59, p<.001]$. These effects interacted $[F(3,45)=12.09, p<.001]$ : The benefit of relatedness was greater for T2 (.14) than for T1 (.04). There was also an interaction between T1/T2 and SOA $[F(1,15)=$ 13.36, $p<.01]$ : The T1 advantage, minimal at an SOA of $27 \mathrm{msec}$, increased markedly as SOA increased. This interaction between SOA and T1/T2 was similar to that observed in experiments reported by Potter et al. (2002).

The triple interaction among relatedness, SOA, and T1/T2 was not significant $(F<1.0)$. Planned comparisons between related and unrelated pairs at each SOA, separately for $\mathrm{T} 1$ and $\mathrm{T} 2$, showed that the only significant benefit of relatedness for $\mathrm{T} 1$ was found at the 27 msec SOA (a benefit of .11, $p<.05$ ). In contrast, T2 benefited from a related T1 at all SOAs $(p<.01)$ and did not vary. Word order was counterbalanced across participants, so it was possible to ask whether the order with the stronger forward association generated more priming. For 82 of the 128 word pairs, both words appeared in Nelson, McEvoy, and Schreiber's (1999) word association norms. In item analyses, the priming effect was no greater for the stronger-first than for the stronger-second order. Thus, overlap of semantic features between the two words, rather than spreading activation from one to the other, is probably the basis of priming in this experiment.

\section{Discussion}

At an SOA of $27 \mathrm{msec}$, the two words compete for processing and, we hypothesize, are about equally likely to be identified first. If we assume that no semantic benefits can obtain until one word has been identified, the relatively equal benefit to $\mathrm{T} 1$ and $\mathrm{T} 2$ at $27 \mathrm{msec}$ is consistent with the supposition that the word that benefited was the one identified second (equally likely to be $\mathrm{T} 1$ or T2). At longer SOAs, T1 was increasingly likely to be identified first, so there was a small but not significant benefit for T1 at an SOA of $53 \mathrm{msec}$ (together with a large benefit for T2) and no benefit for T1 at SOAs of 107 and $213 \mathrm{msec}$. The effect of the T2 benefit at longer SOAs was to reduce, but not eliminate, the AB. Before discussing the possible locus of this priming effect, we report Experiment 2.

\section{EXPERIMENT 2}

Experiment 2 was carried out independently of Experiment 1 , with a similar theoretical question and a similar design, but with Italian participants and materials.

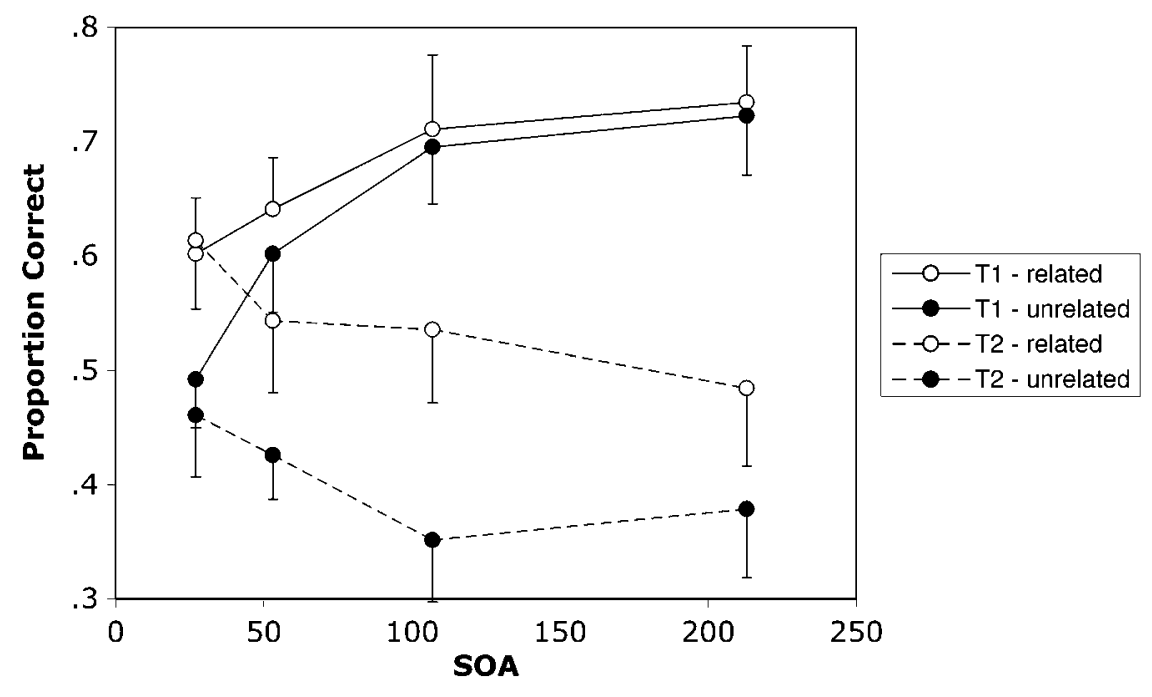

Figure 2. Results of Experiment 1 (English). Error bars represent standard errors. 


\section{Method}

The method was the same as that of Experiment 1, except as specified.

Participants. The 30 participants were graduate or undergraduate students at the University of Padua and were all native Italian speakers. The results of 7 participants were excluded for their low performance on $\mathrm{T} 1[P(\mathrm{~T} 1)<.10]$.

Stimuli and Apparatus. The target stimuli were 144 pairs of four-letter Italian nouns and adjectives selected from the PD-DPSS verbal association norms (Peressotti, Pesciarelli, \& Job, 2002), matched for frequency. Half of the pairs were composed of semantically unrelated words and half of semantically related words. The stimuli were displayed in uppercase black letters on a light gray background, on a 17-in. monitor with a refresh rate of $60 \mathrm{~Hz}$, controlled by a Pentium IV CPU and MEL 2.0 software. At a viewing distance of $50 \mathrm{~cm}$, each stimulus could be inscribed in a rectangular region of $3.2^{\circ} \times 1.1^{\circ}$. The stimuli were displayed in two RSVP streams, separated by $0.5^{\circ}$.

Design and Procedure. Each trial began with fixation crosses at the center of the screen. When the space bar was pressed, a blank interval of $500 \mathrm{msec}$ was followed by the RSVP streams of stimuli, at $50 \mathrm{msec} /$ frame. The distractors were strings of ampersands alternating with strings of percentage signs. Three to five distractors (randomly determined) preceded $\mathrm{T} 1$, and three followed $\mathrm{T} 2$. The two words were displayed simultaneously (at an SOA of 0) or at an SOA of 50,100, or $200 \mathrm{msec}$, within participants. The order of the words in a pair was fixed; for related pairs, the order respected the direction of association. The SOA on a given trial and the order of the trials were randomized separately for each participant, with the constraint that there be equal numbers of trials in each $\mathrm{SOA} /$ relatedness condition.

At the end of each trial, the participants typed the two words, in any order. If at least three of the four letters were correct, the response was considered correct (no words in the list had more than two letters in common). Feedback was given after each trial. There were 16 practice trials.

\section{Results}

The main results are shown in Figure 3. ANOVAs were carried out separately on the SOA $=0$ condition and the three conditions in which the SOA $>0$. Because the words appeared simultaneously in the SOA $=0$ condition, the variable T1/T2 corresponded to sets of stimuli, not to word order. The main effect of word set (T1 vs. T2) was not significant, but there was significantly greater accuracy for words in related pairs than in unrelated pairs $[F(1,22)=22.2, p<.001]$. The interaction was not significant $(p=.33)$, indicating that priming was equivalent in both directions when the words were presented simultaneously, not only in the normative direction of association. In our analysis of the $\mathrm{SOA}>0$ conditions, there were main effects of relatedness $[F(1,22)=38.6$, $p<.001]$, of T1/T2 word $[F(1,22)=19.7, p<.001]$, and of SOA $[F(2,44)=4.0, p<.03]$. There was also a significant interaction between T1/T2 word and SOA $[F(2,44)=18.6, p<.001]$.

There was a significant three-way interaction among these variables $[F(2,44)=5.9, p<.01]$. In separate analyses of $\mathrm{T} 1$ and $\mathrm{T} 2$, the only significant priming effect on $\mathrm{T} 1$ was at an SOA of $50 \mathrm{msec}[F(1,22)=29.4$, $p<.001]$. In contrast, for $\mathrm{T} 2$, there was no priming effect at $50 \mathrm{msec}$, but significant effects at SOAs of 100 and $200 \mathrm{msec}[F(1,22)=5.6, p<.03$, and $F(1,22)=$
$5.8, p<.03$, respectively]. Finally, for unrelated words, there was a marginally significant advantage of $\mathrm{T} 2$ over T1 with an SOA of $50 \mathrm{msec}[F(1,22)=2.1, p<.07]$. Such a crossover was observed in many experiments reported by Potter et al. (2002), although not in the present Experiment 1.

Experiments 1 and 2 provide clear-cut support for the idea that sequential targets in RSVP streams are frequently identified in reversed order at short SOAs. In both experiments, a marked main effect of relatedness was observed, and relatedness only benefited $\mathrm{T} 1$ at SOAs shorter than $100 \mathrm{msec}$. At longer SOAs, relatedness only affected T2. Furthermore, in both experiments there was an interaction between SOA and T1/T2, such that there were minimal differences between $\mathrm{T} 1$ and $\mathrm{T} 2$ report at short SOAs, but T1 dominated increasingly as the SOA increased to 200 or $213 \mathrm{msec}$, the classic SOA for the $\mathrm{AB}$ effect. Relatedness reduced, but did not eliminate, $\mathrm{AB}$.

A difference between the results of the two experiments was observed at an SOA of 50 or $53 \mathrm{msec}$. In Experiment 1 , there was a strong relatedness effect on $\mathrm{T} 2$ but only a slight effect on T1, with the opposite pattern in Experiment 2. It is not clear why this occurred. For unrelated words, there was a T2 advantage in Experiment 2 at a 50 -msec SOA, suggesting that T2 was often identified before T1, whereas in Experiment 1 there was a strong T1 advantage at this SOA. This difference, perhaps associated with the overall lower performance in Experiment 2, may account for the priming of $\mathrm{T} 1$ at this SOA in Experiment 2 only. Why there was no priming of $\mathrm{T} 2$ in Experiment 2 at an SOA of 50-msec is less clear. (In pilot work for Experiment 2, we obtained T2 priming at a $50-\mathrm{msec}$ SOA of the same magnitude as that found at SOAs of 100 and $200 \mathrm{msec}$.) Despite these differences, the overall similarity of the results of these independently designed experiments is clear, including the key finding that $\mathrm{T} 2$ primes $\mathrm{T} 1$ only at very short SOAs, when $\mathrm{T} 2$ is at least as likely to be reported as T1.

\section{GENERAL DISCUSSION}

The purpose of the present study was to use semantic priming as a tool to investigate the interplay between two word targets at short SOAs. Word perception was made difficult by presenting targets for 50 or $53 \mathrm{msec}$ within two streams of distractors and by presenting them close in time (at SOAs between 27 and $213 \mathrm{msec}$ ). Potter et al. (2002) found that the relative accuracy of reporting T1 and T2 varied markedly with SOA over this range, in a way that suggested that $\mathrm{T} 2$ was identified before $\mathrm{T} 1$ at short SOAs. In the present experiments, we varied the semantic relatedness between the two targets, to discover whether priming of a given target reflected the hypothesized order in which the two targets were processed. When the targets were semantically related, both showed a priming benefit at 0 or short SOAs (except that only 


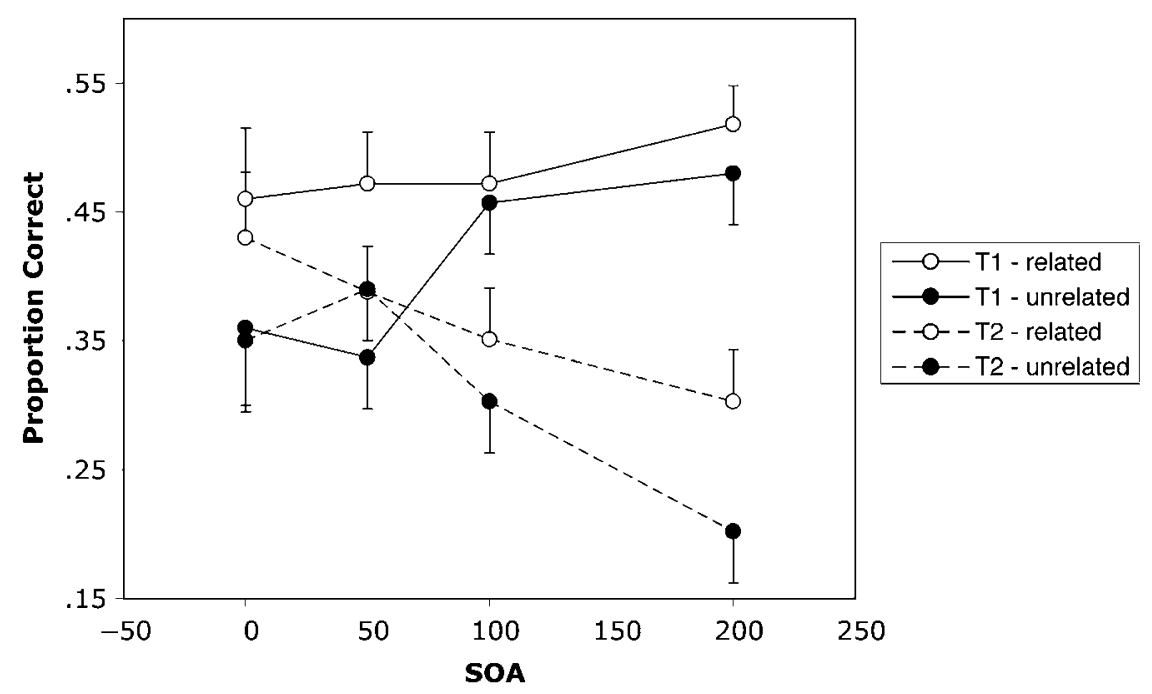

Figure 3. Results of Experiment 2 (Italian). Error bars represent standard errors. For the simultaneous conditions, $\mathrm{T} 1$ and $\mathrm{T} 2$ refer to word sets, not temporal order.

T1 showed a benefit at a 50-msec SOA in Experiment 2). Only T2 benefited from priming at longer SOAs.

These results strongly imply that when words are viewed very briefly and close together in time, priming is functionally unidirectional, from the first word that is identified to the other word. The present evidence supports Potter et al.'s (2002) proposal that, at SOAs < $100 \mathrm{msec}, \mathrm{T} 2$ is often identified before T1.

At what point in processing does the semantic benefit actually occur? Davenport and Potter (2005), using a method of presentation like that in our Experiment 1, primed one of two targets by presenting an associate at the beginning of each trial. They found consistent priming for the related word, regardless of SOA or T1/T2. This result suggested that the priming effect occurred in a processing step independent of T1/T2 and SOA. They concluded that priming boosted word identification (cf. Sereno, Brewer, \& O'Donnell, 2003), prior to Stage 2 consolidation. The same logic suggests that in the present experiments, the semantic context set up by the first identified word (whether T1 or T2) assisted identification of the other word.

Could the priming effect have come later, after Stage 2, at the point of retrieving $\mathrm{T} 1$ and/or T2 from a working memory (WM) buffer (analogous to the cause of the AB proposed by Shapiro, Raymond, \& Arnell, 1994)? That seems unlikely, for several reasons. There is a suppression of the electroencephalographic P300 component when $\mathrm{T} 2$ appears during the $\mathrm{AB}$ interval (Dell'Acqua, Jolicœur, Pesciarelli, Job, \& Palomba, 2003; Vogel et al., 1998). The P300 component is assumed to reflect entry and updating of information into WM (Donchin \& Coles, 1988), so its absence suggests that blinked targets do not enter WM. Furthermore, had the retrieval of one target from WM cued retrieval of the other target on the basis of their semantic relation, $\mathrm{T} 1$ should have benefited from a related $\mathrm{T} 2$ at all SOAs, not just short ones.

When targets were separated by an SOA of $100 \mathrm{msec}$ or greater, only $\mathrm{T} 2$ showed a relatedness benefit. This pattern differs from findings from earlier priming paradigms in which masked primes presented as much as $1 \mathrm{sec}$ before a visible target were more accurately reported when they were related to the target: a backward effect (e.g., Briand, den Heyer, \& Dannenbring, 1988; Dark, 1988). ${ }^{1}$ (There was typically no forward priming benefit to the target unless the prime on that trial was recognized.) The lack of a backward effect in the present experiments at SOAs of $100 \mathrm{msec}$ or longer suggests that our presentation conditions prevented the persistence of any perceptual information about $\mathrm{T} 1$, so that semantic information about $\mathrm{T} 2$ arrived too late to boost identification of T1.

Our findings suggest that the backward priming effect in the present experiments happens rapidly and immediately, or not at all. If $\mathrm{T} 2$ is the first word to be identified, its semantic features are activated quickly. If $\mathrm{T} 1$ shares semantic features with $\mathrm{T} 2$ and is close to the point of identification when this activation occurs (at very short SOAs), it benefits. At longer SOAs, if T1 is not successfully identified, no partial information persists. That is why backward priming of $\mathrm{T} 1$ by a later $\mathrm{T} 2$ does not occur except at very short SOAs at which T2 is often identified first. Thus, the evidence suggests that all semantic priming under these perceptual conditions is functionally forward, from an identified word to a word not yet identified.

\section{REFERENCES}

Briand, K., DEN Heyer, K., \& DANnenbring, G. L. (1988). Retroactive semantic priming in a lexical decision task. Quarterly Journal of Experimental Psychology, 40A, 341-359. 
Broadbent, D. E., \& Broadbent, M. H. P. (1987). From detection to identification: Response to multiple targets in rapid serial visual presentation. Perception \& Psychophysics, 42, 105-113.

Chun, M. M., \& PotTer, M. C. (1995). A two-stage model for multiple target detection in rapid serial visual presentation. Journal of Experimental Psychology: Human Perception \& Performance, 21, 109-127.

DARK, V. J. (1988). Semantic priming, prime reportability, and retroactive priming are interdependent. Memory \& Cognition, 16, 299-308.

DavenPort, J., \& PotTer, M. C. (2005). The locus of semantic priming in RSVP target search. Memory \& Cognition, 33, 241-248.

Dell'Acqua, R., Joliceur, P., Pesciarelli, F., Job, R., \& Palomba, D. (2003). Electrophysiological evidence of visual encoding deficits in a crossmodal attentional blink paradigm. Psychophysiology, 40, 629639.

Dell'Acqua, R., Pascali, A., Jolicceur, P., \& Sessa, P. (2003). Fourdot masking produces the attentional blink. Vision Research, $\mathbf{4 3}$, 1907-1913.

Donchin, E., \& Coles, M. G. H. (1988). Is the P300 component a manifestation of context updating? Behavioral \& Brain Sciences, 11, 357374.

Hunt, S. M. J. (1994). MacProbe: A Macintosh-based experimenter's workstation for the cognitive sciences. Behavior Research Methods, Instruments, \& Computers, 26, 345-351.

Jolicceur, P., \& Dell'Acqua, R. (1998). The demonstration of shortterm consolidation. Cognitive Psychology, 36, 138-202.

Juola, J. F., Duvuru, P., \& Peterson, M. S. (2000). Priming effects in attentional gating. Memory \& Cognition, 28, 224-235.

KIgER, J. I., \& Glass, A. L. (1983). The facilitation of lexical decisions by a prime occurring after the target. Memory \& Cognition, 11, 356365.

Maki, W. S., Frigen, K., \& Paulson, K. (1997). Associative priming by targets and distractors during rapid serial visual presentation: Does word meaning survive the attentional blink? Journal of Experimental Psychology: Human Perception \& Performance, 23, 1014-1034.

Nelson, D. L., McEvoy, C. L., \& Schreiber, T. (1999). The University of South Florida word association, rhyme, and word fragment norms. Available at http://cyber.acomp.usf.edu/FreeAssociation/.

Peressotti, F., Pesciarelli, F., \& Job, R. (2002). Le associazioni verbali PD-DPSS: Norme per 294 parole [PD-DPSS Verbal associations: Norms for 294 words]. Giornale Italiano di Psicologia, 29, 153-170.
PotTer, M. C. (1999). Understanding sentences and scenes: The role of conceptual short term memory. In V. Coltheart (Ed.), Fleeting memories (pp. 13-46). Cambridge, MA: MIT Press.

Potter, M. C., Chun, M. M., Banks, B. S., \& Muckenhoupt, M. (1998). Two attentional deficits in serial target search: The visual attentional blink and an amodal task-switch deficit. Journal of Experimental Psychology: Learning, Memory, \& Cognition, 24, 979-992.

Potter, M. C., Staub, A., \& O'Connor, D. H. (2002). The time course of competition for attention: Attention is initially labile. Journal of Experimental Psychology: Human Perception \& Performance, 28, 1149-1162.

Raymond, J. E., Shapiro, K. L., \& Arnell, K. M. (1992). Temporary suppression of visual processing in an RSVP task: An attentional blink? Journal of Experimental Psychology: Human Perception \& Performance, 18, 849-860.

Rolke, B., Heil, M., Streb, J., \& Hennighausen, E. (2001). Missed prime words within the attentional blink evoke an N400 semantic priming effect. Psychophysiology, 38, 165-174.

Sereno, S. C., Brewer, C. C., \& O'Donnell, P. J. (2003). Context effects in word recognition: Evidence for early interactive processing. Psychological Science, 14, 328-333.

Shapiro, K. L., Raymond, J. E., \& Arnell, K. M. (1994). Attention to visual pattern information produces the attentional blink in rapid serial visual presentation. Journal of Experimental Psychology: Human Perception \& Performance, 20, 357-371.

Vogel, E. K., LuCK, S. J., \& Shapiro, K. L. (1998). Electrophysiological evidence for a postperceptual locus of suppression during the attentional blink. Journal of Experimental Psychology: Human Perception \& Performance, 24, 1656-1674.

\section{NOTE}

1. When Kiger and Glass (1983) presented a semantic prime $50 \mathrm{msec}$ after a target word to which the participant made a lexical decision, a backward priming effect was observed. However, the stimuli were not masked and the prime was not reported; nor was the order of presentation varied.

(Manuscript received April 7, 2004; revision accepted for publication August 23, 2004.) 